\title{
Effect of Oxygen on Sputtered Tantalum Nitride Thin Films for Photoelectrochemical Water Splitting
}

\author{
Sam Macartney ${ }^{1}$, Richard Wuhrer ${ }^{2}$ and Leigh R. Sheppard ${ }^{1}$
}

1. School of Computing, Engineering and Mathematics, Western Sydney University, Penrith, Australia

2. Advanced Materials Characterisation Facility, Office of the Deputy Vice-Chancellor \& Vice-President (Research \& Development), Western Sydney University, Penrith, Australia

With the rising pressure of climate change pushing research into various areas of renewable energy sources, solar generated hydrogen represents a compelling research avenue. Using solar hydrogen farms, it would be possible to generate enough hydrogen from water and sunlight to support a theoretical hydrogen economy[1]. Since the discovery of photocatalytic water splitting using $\mathrm{TiO}_{2}[2]$, four decades of research has focused on developing efficient solar to hydrogen water splitting technologies. However, despite large improvements in the capabilities of $\mathrm{TiO}_{2}$, efficient water splitting devices utilising it and other oxides have not eventuated.

In recent years, various nitride materials have been highlighted as possessing great potential for efficient water splitting[3]. Tantalum nitride, specifically $\mathrm{Ta}_{3} \mathrm{~N}_{5}$, is one such nitride, possessing appropriate band edge positions for efficient, bias free overall water splitting and a band gap allowing absorption of visible light[4].

The goal of this project is to deposit thin films of $\mathrm{Ta}_{3} \mathrm{~N}_{5}$ for use in photo-electrochemical cells as novel photo-electrodes. In the current literature, nearly all reports include the use of oxygen in the synthesis of $\mathrm{Ta}_{3} \mathrm{~N}_{5}$, whether thermal nitridation or sputtering routes. The formation of these films is catalyzed by oxygen due to the tendency of high oxidation state transition metals, in this case $\mathrm{Ta}^{5+}$, to draw stability from the inductive effect of a more electronegative element[5]. As such, the role of oxygen in the synthesis of $\mathrm{Ta}_{3} \mathrm{~N}_{5}$ is important and warrants investigation.

A number of films were deposited via RF sputtering with the deposition parameters listed in Table 1, using an AJA Orion 5 magnetron sputtering system (AJA International, Scituate MA). A film of tantalum was deposited prior to oxygen and nitrogen being introduced into the atmosphere. Surface feature imaging and elemental quantification was performed with a JEOL JSM-7001F (JEOL, Tokyo, Japan) Scanning Electron Microscopy (SEM) equipped with a Bruker XFlash 6I10 (Bruker, MA) detector for Electron-Dispersive Spectroscopy (EDS).

Oxygen presence in the sputtering atmosphere had an impact on surface structure, elemental composition and film thickness. X-Ray Diffraction (not displayed) indicated the presence of $\mathrm{Ta}_{3} \mathrm{~N}_{5}$ in the two films with lowest oxygen partial pressures $\left(p\left(\mathrm{O}_{2}\right)\right)$, with a phase transition to TaN taking place at the highest $p\left(\mathrm{O}_{2}\right)$. Figure 1 displays surface structures (below) and film cross sections (above). Surface roughness gradually decreased with increasing $p\left(\mathrm{O}_{2}\right)$, due to the increasingly amorphous nature of the films. The $p\left(\mathrm{O}_{2}\right)$ correlated to the presence of oxygen within the films, however even with a $p\left(\mathrm{O}_{2}\right)$ of 0 mTorr, a not insignificant amount of oxygen was still detected in the films; the source of this is still to be determined. Despite the $p\left(\mathrm{O}_{2}\right)$ matching the nitrogen partial pressure $\left(p\left(N_{2}\right)\right)$ at 0.3 mTorr, a larger amount of nitrogen was still observed in the films, suggesting a decrease in oxygen gettering at higher 
$p\left(\mathrm{O}_{2}\right)$ values. The observation of TaN at $p\left(\mathrm{O}_{2}\right)=0.3 \mathrm{mT}$ Torr further indicates this. This data provides a basic view of the relationship between oxygen, nitrogen and tantalum in our systems atmosphere while utilising RF magnetron sputtering. It is apparent that oxygen must be controlled to within a few $\%$ of the total sputtering atmosphere in order to deposit $\mathrm{Ta}_{3} \mathrm{~N}_{5}$ films.

\section{References:}

[1] Katsushi, F., K. Takeshi, and O. Kazuhiro, Japanese Journal of Applied Physics 44(4L) (2005), p. L543.

[2] Fujishima, A. and K. Honda, Nature 238 (5385) (1972), p. 37.

[3] Maeda, K. and K. Domen, The Journal of Physical Chemistry Letters 1(18) (2010), p. 2655.

[4] Hitoki, G. et al, Chemistry Letters 31(7) (2002), p. 736.

[5] Rudolph, M. et al, The role of oxygen in magnetron-sputtered Ta3N5 thin films for the photoelectrolysis of water. Surface and Coatings Technology.

Table 1. Processing parameters for Ta, $\mathrm{O}, \mathrm{N}$ based films deposited with varying $p\left(\mathrm{O}_{2}\right)$, and the resulting film thickness and composition. EDS was performed with an accelerating voltage of $5 \mathrm{kV}$.

\begin{tabular}{|c|c|c|c|c|c|c|c|c|}
\hline $\begin{array}{c}p(A r): p\left(N_{2}\right): p\left(O_{2}\right) \\
(m T o r r)\end{array}$ & $\begin{array}{c}\text { Deposition } \\
\text { Pressure } \\
\text { (mTorr) }\end{array}$ & $\begin{array}{c}\text { Film } \\
\text { Thickness } \\
\text { (nm) }\end{array}$ & $\begin{array}{l}\text { Dep. Rate } \\
\text { (nm/min) }\end{array}$ & $\begin{array}{l}\text { Bias } \\
(V)\end{array}$ & $\begin{array}{r}T_{\text {sub }} \\
\left({ }^{\circ} \mathrm{C}\right)\end{array}$ & $\begin{array}{l}{[\mathrm{N}]} \\
\text { (at. } \\
\% \text { ) }\end{array}$ & $\begin{array}{l}\text { [Ta] } \\
\text { (at. } \\
\%)\end{array}$ & $\begin{array}{l}\text { [O] } \\
\text { (at. } \\
\% \text { ) }\end{array}$ \\
\hline 2.4:0.3:0.3 & 3 & 463 & 1.54 & 280 & 700 & 41 & 29 & 30 \\
\hline $2.67: 0.3: \mathbf{0 . 0 3}$ & 3 & 403 & 1.34 & 280 & 700 & 55 & 31 & 14 \\
\hline $2.7: 0.3: 0$ & 3 & 611 & 2.03 & 280 & 700 & 53 & 35 & 12 \\
\hline
\end{tabular}

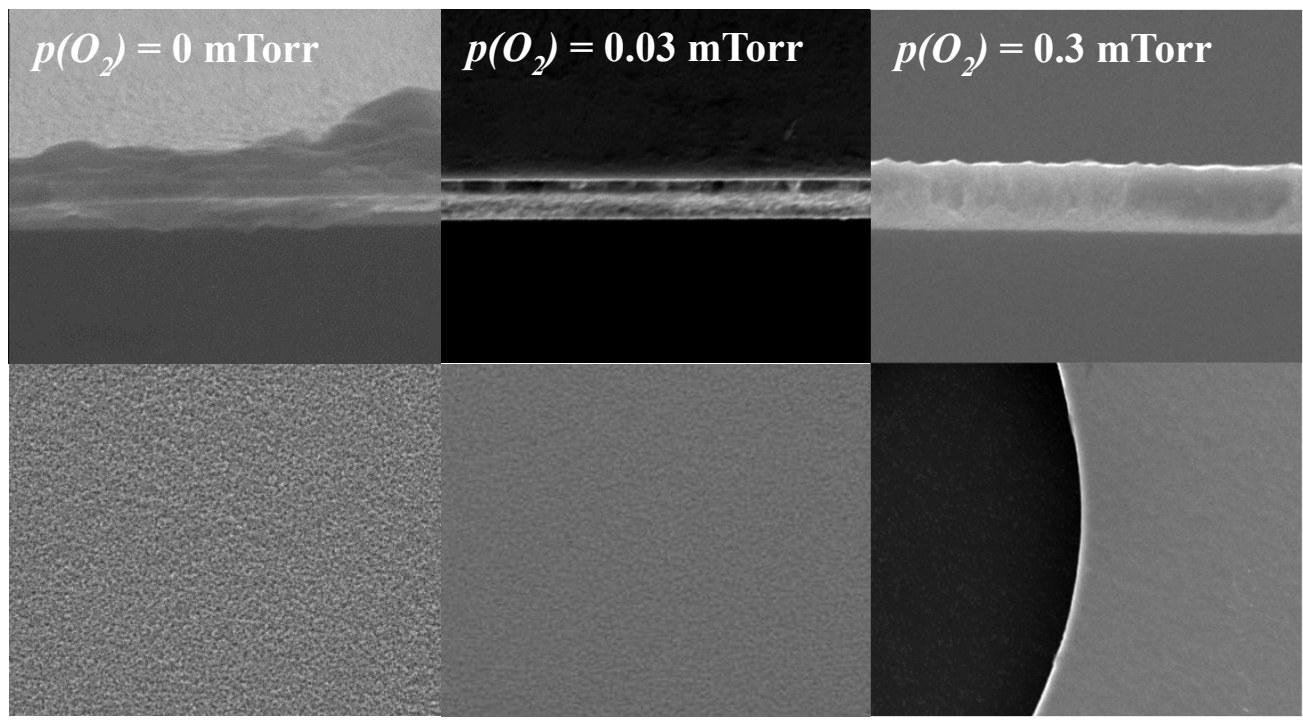

Figure 1. SEM images showing surface features of Ta, $\mathrm{O}, \mathrm{N}$ based films deposited with varying $p\left(O_{2}\right)$ values. Images were taken at $10,000 \mathrm{x}$, with a working distance of $10 \mathrm{~cm}$ and accelerating voltage of $10 \mathrm{kV}$. 